\title{
"Mi casa es esta pieza": migración femenina y precariedad habitacional en la Ciudad de Buenos Aires
}

\author{
"My house is this room": female migration and precarious housing \\ in the City of Buenos Aires
}

\author{
Juliana Marcús * \\ * Universidad de Buenos Aires- CONICET, Argentina | julimarcus@gmail.com
}

\section{PALABRAS CLAVE}

Precariedad habitacional

Hoteles-pensión

Migración femenina

Ciudad de Buenos Aires

KEYWORDS

Precarious housing

Boarding houses

Female migration

City of Buenos Aires

\section{RESUMEN}

El objetivo de este artículo es analizar, por un lado, el escenario migratorio de nueve mujeres y sus familias tomando en consideración las motivaciones de la migración y el proceso de desplazamiento desde sus lugares de origen hacia la Ciudad de Buenos Aires y, por otro lado, el proceso de integración en la sociedad receptora desde su residencia en hoteles-pensión de la ciudad capital. Esta modalidad del hábitat popular urbano, junto con los conventillos, inquilinatos, villas miseria, asentamientos y casas tomadas pone de relieve la precariedad habitacional de la ciudad. Se realizaron entrevistas en profundidad y observaciones participantes en los hoteles-pensión.Uno de los resultados obtenidos es que la ausencia de propuestas integradoras de política habitacional dirigidas a los sectores populares, sobre todo migrantes internos y de países limítrofes, incide en la falta de acceso a la vivienda digna. En este sentido, el Estado se desentiende en cuanto a políticas habitacionales destinadas a la integración. Las mujeres migrantes entrevistadas han sido seducidas y atraídas por los beneficios que otorga la gran ciudad y simultáneamente abandonadas por el Estado, pues los mecanismos de recepción y albergue son sumamente escasos. No sólo se les niega el derecho a la ciudad sino también se las despoja del derecho a una vivienda digna y se las "condena” a vivir en viviendas precarias o en los márgenes de la ciudad.

\section{ABSTRACT}

The purpose of this paper is to analyze the migratory scenario of nine women and their families taking into account the motivations of the migration and the process of displacement from their places of origin towards the City of Buenos Aires. In addition, this paper analyzes process of integration into the receiving society from his residence in bourding houses of the capital city. This modality of the urban habitat, together with the conventillos, "villas miseria" and occupied houses, highlights the precarious housing of the city. In-depth interviews and participant observations were carried out at bourding houses. One of the results obtained is that the lack of housing policy proposals aimed at the popular sectors, especially internal migrants and neighboring countries, has an impact on the lack of access to decent housing. In this sense, the State disagrees with regard to housing policies aimed at integration. The migrant women interviewed have been seduced and attracted by the benefits of the great city and simultaneously abandoned by the State, since there is no mechanism of reception and shelter. Not only are they denied the right to the city, but they are also deprived of the right to decent housing and "condemned" to live in precarious housing or on the margins of the city.

Fecha de recibido: 09/06/2017 | Fecha de aceptado: 24/08/2017 | Fecha de publicado: 28/12/2017

Cita sugerida: Marcús, J. (2017). “Mi casa es esta pieza”: migración femenina y precariedad habitacional en la Ciudad de Buenos Aires. Cuestiones de Sociología, 17, e040. https://doi.org/10.24215/23468904e040 


\section{Introducción}

El acceso a una vivienda digna es un derecho consagrado en el artículo 31 de la Constitución de la Ciudad de Buenos Aires. Sin embargo, más de 400.000 personas residentes en esta urbe, aproximadamente el 15 \% de la población total de la ciudad, tienen serios problemas habitacionales, es decir, no gozan de aquel derecho. Para esta porción de la población, el acceso a la vivienda se convierte en una ardua e incesante lucha cotidiana: 163.587 personas viven en las villas miseria de la ciudad (Dirección General de Estadística y Censos, GCBA, 2011; Herzer y Di Virgilio, 2011), 12.000 residen en los llamados Nuevos Asentamientos Urbanos ${ }^{\underline{1}}, 65.000$ habitan en conventillos e inquilinatos, y otras 40.000 lo hacen en hoteles y pensiones (Instituto Nacional de Estadística y Censos, 2010). A esta población se suman 79.000 personas que viven en inmuebles ocupados (Rodríguez, 2006; citado en Carman, 2006, p. 68), 120.000 se alojan en viviendas de familiares, en habitaciones rentadas o hacinadas en vivienda propia (Dirección General de Estadística y Censos, GCBA, 2011) y alrededor de 5.000 duermen en las calles porteñas (Rosa, 2012), fenómeno que se torna cada vez más intenso y visible. Una de las poblaciones más vulnerables en cuanto al acceso a la vivienda digna son las familias de sectores populares encabezadas por mujeres que han migrado en las últimas décadas desde la zona de Cuyo, el Norte y el Litoral argentinos hacia Buenos Aires.

En este artículo analizamos, por un lado, el escenario migratorio de nueve mujeres y sus familias tomando en consideración las motivaciones de la migración y el proceso de desplazamiento desde sus lugares de origen y, por otro lado, el proceso de integración en la sociedad receptora teniendo en cuenta su lucha cotidiana por permanecer en la ciudad. Se trata de mujeres que habitan hace ya muchos años en Buenos Aires, que desde que llegaron a la ciudad comenzaron a deambular por casas de familiares y que, más tarde, lo hicieron por diversos hoteles-pensión de la ciudad capital, aprendiendo a vivir en la inestabilidad habitacional. Esta modalidad del hábitat popular urbano, junto con los conventillos, inquilinatos, villas miseria, asentamientos y casas tomadas supone un modo precario de habitar en la ciudad.

En la última década, el conflicto alrededor del acceso al suelo urbano recrudeció. El crecimiento inmobiliario y de la construcción y la lógica especulativa del mercado han incrementado el valor del suelo, el de los alquileres y el valor de los inmuebles restringiendo aún más el acceso a la vivienda de los sectores con menores recursos económicos. En la Ciudad de Buenos Aires, los precios del suelo subieron un $300 \%$ de junio de 2004 a junio de $2013^{2}$. Además, los elevados precios del suelo desplazan a los sectores populares a zonas cada vez más alejadas y marginadas. Las ocupaciones de tierras y viviendas, sumadas a la expansión de habitaciones en las construcciones de mala calidad de las villas miseria, han representado en la historia reciente la forma más común de acceso al suelo y a la vivienda para los sectores populares. A estas formas precarias de habitar la ciudad se suma la falta de respuestas a la problemática de la emergencia habitacional por parte de las diferentes gestiones del Gobierno de la Ciudad de Buenos Aires (GCBA) en los últimos años (Marcús, 2017; Baer y Kauw, 2016; Cuenya, 2016; Cosacov, 2012).

En este contexto se enmarcan las historias de las mujeres migrantes entrevistadas que llegaron a la ciudad con la esperanza de mejorar su calidad de vida. Sus estrategias habitacionales se definen en la intersección entre necesidades y expectativas habitacionales de los hogares, y los condicionantes estructurales asociados a las políticas sociohabitacionales y a la dinámica del mercado de trabajo 
(Di Virgilio y Gil y De Anso, 2012).

Los datos analizados en este trabajo fueron reunidos durante cinco períodos de trabajo de campo durante una investigación doctoral -de una duración estimada de dos meses cada uno- entre septiembre de 2004 y febrero de 2009. Para describir y analizar el proceso migratorio de estas mujeres utilizamos el método biográfico (Sautu, 2004) consistente en el despliegue de sucesos de vida y experiencias a lo largo del tiempo, articulados con el contexto inmediato y vinculados a historias de vida de otras personas con quienes estas mujeres han construidos lazos sociales (la familia, la escuela, el barrio, el trabajo, las ONGs, las cooperativas, etc.). El objetivo fue capturar la perspectiva microsocial y contextualizarla históricamente. Se utilizó la entrevista en profundidad como procedimiento de registro y obtención de narraciones de nueve mujeres elegidas mediante las técnicas de muestreo teórico y bola de nieve. Se realizaron 45 entrevistas en profundidad con un promedio de 5 encuentros por mujer. Los encuentros fueron prolongados en el tiempo y las entrevistas se llevaron a cabo en más de una oportunidad. Cada entrevista tuvo una duración aproximada de dos horas.

Focalizamos en dos grandes etapas de su vida: la socialización en sus lugares de origen (zonas urbanas y semiurbanizadas) y el espacio de resocialización durante los últimos 15 años (hotelespensión ubicados en zonas céntricas de la urbe porteña). Se tuvieron en cuenta las orientaciones culturales, la pertenencia a una cohorte de edad, la situación habitacional, las decisiones de los actores que han moldeado sus cursos de vida, la reconstrucción de la trayectoria migratoria, las relaciones sociales con diversas “otredades”, la relación con las instituciones del Estado, entre otras cuestiones.

Asimismo adoptamos los supuestos metodológicos de Clifford Geertz, procurando aplicar el modelo de la "descripción densa" a las historias de las mujeres y tratando de realizar “interpretaciones de interpretaciones de los nativos sobre lo que ellos piensan y sienten”(Geertz, 1987, p. 23).

Durante el mismo período de trabajo de campo, hemos completado las narrativas de los sujetos con la observación participante en hoteles-pensión ubicados en los barrios porteños de Barracas, Congreso, Constitución, Flores y Balvanera, ubicados en el sur de la ciudad, llevando minucioso registro de lo observado y detectado, así como de las descripciones y hallazgos.

\section{Mujeres migrando a la ciudad}

Las migraciones femeninas estudiadas en este artículo se produjeron entre 1970 y 1997, período en el que las estadísticas revelan una merma en las migraciones, tanto internas como internacionales, debido a una retracción en la economía argentina (Elizalde, 1987; Lattes, 2007). Sus desplazamientos no se pueden explicar como olas o corrientes migratorias sino que forman parte de lo que hemos llamado movimientos migratorios permanentes (Marcús, 2009, 2011), muchas veces inestables.

Las nueve mujeres entrevistadas emigraron en diferentes etapas de su vida y con motivaciones diversas -condiciones de empleo, mejoras en la calidad de vida, separaciones familiares, enfermedad de algún pariente, etc. - desde zonas rurales y semiurbanizadas de las provincias 
argentinas de Mendoza, Córdoba, San Juan, Corrientes, Santa Fe, Salta y Tucumán hacia la Ciudad de Buenos Aires. Se han tenido en cuenta tanto el aspecto microsocial de los procesos migratorios femeninos, es decir, el estudio de los sujetos y grupos familiares (Jelin, 1976; Recchini de Lattes, 1988; Freidin, 2004; Mallimaci Barral, 2013), como el nivel macrosocial: el contexto socioeconómico en el que se insertan estos desplazamientos.

Los casos analizados se produjeron en un escenario que se caracterizó por la crisis económica iniciada a fines de los años '70 y agudizada en los años '80 con un descenso sostenido del producto bruto interno, lo que deprimió las condiciones de vida y elevó los niveles de pobreza. La década del '90 introdujo grandes cambios en el plano económico y "hacia fines de esa década se profundizaron la pobreza y la desigualdad en la distribución del ingreso al mismo tiempo que se deterioraron las condiciones del mercado de trabajo” (Maguid, 2005, p. 253). Las mujeres entrevistadas se desplazaron en un contexto económico-político de mutaciones del capitalismo iniciadas en la década del '70 y profundizadas durante la década del '90, resultantes de la aplicación y el impacto en la Argentina de las llamadas "recetas neoliberales" -liberalización de la economía, reforma del Estado, Plan de Convertibilidad, desindustrialización, privatizaciones, apertura comercial, entre otras políticas. Como corolario del modelo económico vigente durante los años '90, aumentaron la pobreza, la desocupación, la precarización laboral y la fragmentación social, lo que impactó en el debilitamiento de los lazos sociales (Sennet, 2000; Svampa, 2005).

Las transformaciones regulatorias y la dinámica macroeconómica de los años '70 durante la última dictadura militar - consolidadas en los años ’90- afectaron fuertemente las bases productivas de la gran mayoría de las economías provinciales provocando altas tasas de desocupación. Como consecuencia de un modelo de concentración económica y flexibilidad laboral se produjeron profundos cambios en el mercado de trabajo (Cacopardo, 2005). La desintegración social y el desamparo por la falta de empleo en sus provincias de origen fueron algunas de las causas principales que motivaron los desplazamientos de las mujeres entrevistadas hacia la Ciudad de Buenos Aires, sobre todo aquellas que migraron con su familia de origen.

Pero la decisión de migrar no sólo se vincula a causas económicas (desocupación en sus lugares de origen, bajos salarios, malas condiciones de empleo), también prevalecen los deseos de cambiar de vida (encontrar mejores oportunidades laborales, distanciarse del ambiente tradicional de su comunidad de origen, mejorar las condiciones educacionales y sanitarias, cumplir el sueño de la "casa propia”, alcanzar aspiraciones y movilidad mayores para ellas y sus hijos, etc.) y el alejamiento de los conflictos familiares (separaciones, escapes, enfermedad de algún pariente, intención de reunirse con otros miembros de la familia, etc.).

La migración también funciona como parte de las estrategias de supervivencia (Di Virgilio y Gil y De Anso, 2012) de la unidad doméstica, puesto que contribuye a tratar de mejorar las condiciones de vida del grupo familiar. Elizabeth Jelin (1976) señala que las mujeres migran más que los varones. Los estudios sobre migración desde una perspectiva de género "ponen de relieve la necesidad de analizar el grado de participación de la mujer en la decisión de migrar, tanto cuando se refiere a sí misma como a otros miembros del grupo familiar” (Riley y Gardner, 1993; citado en Dabenigno y Freidin, 1997, p. 89). Según Marcela Cerrutti (2009), la feminización de los flujos migratorios ha sido considerada como parte de un proceso de cambio global que ha afectado las 
condiciones de vida de vastos sectores de la población en países en desarrollo. De acuerdo con Ana Mallimaci (2012, p. 154), la feminización de las migraciones

\begin{abstract}
...hace hincapié en dos dimensiones centrales: un aumento cuantitativo de las mujeres en las migraciones y un cambio cualitativo en su rol dentro de las migraciones. No se trata únicamente de un aumento en la cantidad de mujeres migrantes, sino de su participación como pioneras del movimiento, es decir, como el primer eslabón de la cadena migratoria.
\end{abstract}

Los desplazamientos llevados a cabo por siete de las nueve mujeres entrevistadas pueden ser contemplados desde la perspectiva de la participación femenina en los procesos migratorios: Lidia y Susana ${ }^{3}$ migraron solas; Adriana y Roxana lo hicieron con su madre; Alicia llegó a Buenos Aires con su tía, y María y Cristina arribaron a la ciudad con sus hijos ya adultas. Las dos mujeres restantes, Marta y Silvia, se trasladaron por decisión de su familia de origen completa (madre, padre y hermanos).

Los determinantes sociales y las modalidades de las migraciones femeninas suelen ser muy específicos según los distintos momentos históricos y las regiones estudiadas. En la Argentina no se pueden soslayar las consecuencias del neoliberalismo sobre las economías regionales y sus efectos (altos niveles de desocupación, precarización e inestabilidad laboral) sobre las migraciones de mujeres. En general, las jóvenes migrantes hacia áreas urbanas suelen realizar tareas manuales, en especial asociadas al servicio doméstico (Maguid y Arruñada, 2005). De hecho las mujeres entrevistadas que se encuentran ocupadas desarrollan dicha labor.

Según Jelin (1976), dos categorías se destacan en las migraciones femeninas: las integradas por mujeres que llegan solas e ingresan al servicio doméstico remunerado, y aquellas mujeres que llegan con sus familias de procreación y realizan tareas domésticas no remuneradas en el seno de sus familias. Freidin (2004) agrega una categoría a las planteadas por Jelin: las mujeres que migran con su grupo familiar de origen. Las edades al momento de la migración, su lugar de procedencia, el año de llegada a la Ciudad de Buenos Aires, las razones del desplazamiento y los itinerarios migratorios son algunos aspectos que definen y configuran los tipos de migración.

Lidia y Susana corresponden a la categoría de mujeres que migraron solas. Lidia, oriunda de la provincia de Salta, llegó a Buenos Aires en 1970 con apenas 15 años, luego de la muerte de su madre. El traslado no fue por decisión propia, pues siendo la penúltima de diez hermanos "debía obedecer a los mayores” y sus hermanos le compraron un pasaje a Buenos Aires si consultarle. Desde entonces trabaja en el servicio doméstico. Susana nació en Corrientes. Arribó a la ciudad Capital en 1993, a los 16 años, con su hijo de tres meses de edad para trabajar cama adentro en el servicio doméstico. Para Susana, la razón del desplazamiento fue mejorar su calidad de vida y la de su hijo, sobre todo en lo que respecta a la educación escolar: "en Corrientes no hay la educación que le dan acá, o sea pueden estudiar pero no es el mismo nivel”. Al igual que Lidia ha vivido en casas de parientes, hoteles-pensión e inquilinatos porteños. A menudo las redes de familiares y allegados que se extienden en Buenos Aires -en general compuestas por comprovincianos que han migrado con anterioridad- facilitan la recepción de los nuevos migrantes, suministrando alojamiento provisorio, informaciones necesarias y contactos posibles para conseguir el primer empleo. Además, 
estos grupos de comprovincianos funcionan como apoyo emocional, como soporte afectivo que brinda protección y refugio frente al nuevo mundo social (Cacopardo y López, 1997) (ver Cuadro 1).

\section{Cuadro 1}

Las mujeres entrevistadas que migraron solas hacia Buenos Aires

\begin{tabular}{|l|l|l|l|l|l|l|}
\hline Nombre & $\begin{array}{l}\text { Edad al } \\
\text { momento de } \\
\text { la migración }\end{array}$ & $\begin{array}{l}\text { Año de } \\
\text { legada a } \\
\text { Buenos } \\
\text { Aires }\end{array}$ & $\begin{array}{l}\text { Lugar de } \\
\text { origen }\end{array}$ & $\begin{array}{l}\text { Razones del } \\
\text { desplazamiento }\end{array}$ & $\begin{array}{l}\text { Cantidad de } \\
\text { años en } \\
\text { Ciudad de } \\
\text { Buenos Aires } \\
\text { al momento } \\
\text { de la } \\
\text { entrevista }\end{array}$ & $\begin{array}{l}\text { Edad al } \\
\text { momento de } \\
\text { la entrevista }\end{array}$ \\
\hline Lidia & 15 años & 1970 & Salta (rural) & $\begin{array}{l}\text { Muerte de la } \\
\text { madre/cambiar de } \\
\text { vida/trabajo doméstico } \\
\text { cama adentro. Su primer } \\
\text { destino fue Caseros, } \\
\text { Prov.de Buenos Aires. } \\
\text { Cuatro años más tarde se } \\
\text { mudó a Capital Federal. }\end{array}$ & 37 & $\begin{array}{l}52 \text { años en } \\
\text { en }\end{array}$ \\
\hline Susana & 16 años & 1993 & $\begin{array}{l}\text { Corrientes } \\
\text { (semi- } \\
\text { urbano) }\end{array}$ & $\begin{array}{l}\text { Trabajo. Llegó a la } \\
\text { ciudad capital con una } \\
\text { vecina del barrio en } \\
\text { Corriente para trabajar en } \\
\text { el servicio doméstico } \\
\text { cama adentro. }\end{array}$ & 13 & $\begin{array}{l}29 \text { años } \\
\text { en }\end{array}$ \\
\hline
\end{tabular}

Fuente: cuadros de elaboración propia en base al trabajo de campo realizado entre 2004 y 2009 en Ciudad de Buenos Aires.

Entre las entrevistadas que migraron con su familia de origen están las que se desplazaron sólo con su madre y hermanos, con su grupo familiar completo o con un pariente. Adriana y Roxana provienen de hogares disueltos por la separación de sus padres. Entre 1978 y 1980 migraron junto a su madre y sus hermanos como un recurso para dejar atrás una historia familiar conflictiva. Marta y Silvia se desplazaron con su grupo familiar completo. Los desplazamientos se produjeron desde Mendoza y Córdoba respectivamente, para mejorar las condiciones laborales del padre o para reencontrarse con parientes; su migración se produjo en la década del '80. Alicia emigró de Tucumán a los 6 años junto a su tía paterna, luego del abandono sufrido de sus padres. Todas ellas participaron de una decisión migratoria ajena, es decir, el desplazamiento no se produjo por propia decisión (Ver cuadro 2). 


\section{Cuadro 2}

Las mujeres entrevistadas que migraron hacia Buenos Aires con su grupo familiar de origen

\begin{tabular}{|c|c|c|c|c|c|c|}
\hline Nombre & $\begin{array}{l}\text { Edad al } \\
\text { momento de } \\
\text { la migración }\end{array}$ & $\begin{array}{l}\text { Año de } \\
\text { llegada a } \\
\text { Buenos } \\
\text { Aires }\end{array}$ & $\begin{array}{l}\text { Lugar de } \\
\text { origen }\end{array}$ & $\begin{array}{l}\text { Razones del } \\
\text { desplazamiento }\end{array}$ & $\begin{array}{l}\text { Cantidad de } \\
\text { años en } \\
\text { Ciudad de } \\
\text { Buenos Aires } \\
\text { al momento } \\
\text { de la } \\
\text { entrevista }\end{array}$ & $\begin{array}{l}\text { Edad al } \\
\text { momento } \\
\text { de la } \\
\text { entrevista }\end{array}$ \\
\hline Marta & 17 años & 1980 & $\begin{array}{l}\text { Mendoza } \\
\text { (urbano) }\end{array}$ & $\begin{array}{l}\text { Reencuentro con familiares } \\
\text { del padrastro. Llegó con } \\
\text { grupo familiar completo. }\end{array}$ & 27 & $\begin{array}{l}44 \text { años en } \\
2007\end{array}$ \\
\hline Adriana & 5 años & 1985 & $\begin{array}{l}\text { Córdoba } \\
\text { (urbano) }\end{array}$ & $\begin{array}{l}\text { Separación de los padres y } \\
\text { problemas económicos } \\
\text { familiares. A los } 5 \text { años } \\
\text { arribó a la Prov. de Buenos } \\
\text { Aires con su madre y sus } \\
\text { hermanos. A los } 16 \text { años se } \\
\text { mudó a la Capital Federal. }\end{array}$ & 22 & $\begin{array}{l}38 \text { años en } \\
2007\end{array}$ \\
\hline Alicia & 6 años & 1979 & $\begin{array}{l}\text { Tucumán } \\
\text { (rural) }\end{array}$ & $\begin{array}{l}\text { Educación. Llegó con una } \\
\text { tía. }\end{array}$ & 30 & $\begin{array}{l}36 \text { años en } \\
2009\end{array}$ \\
\hline Silvia & 13 años & 1984 & $\begin{array}{l}\text { Córdoba } \\
\text { (urbano) }\end{array}$ & $\begin{array}{l}\text { Trabajo del padre. Llegó con } \\
\text { el grupo familiar completo. } \\
\text { Su primer destino fue La } \\
\text { Matanza, Prov. de Buenos } \\
\text { Aires. Dos años después se } \\
\text { mudaron al barrio porteño } \\
\text { de Flores. }\end{array}$ & 24 & $\begin{array}{l}37 \text { años en } \\
2008\end{array}$ \\
\hline Roxana & 3 años & 1978 & $\begin{array}{l}\text { San Juan } \\
\text { (urbano) }\end{array}$ & $\begin{array}{l}\text { Problemas económicos. } \\
\text { Llegó sólo con su madre. }\end{array}$ & 29 & $\begin{array}{l}32 \text { años en } \\
2007\end{array}$ \\
\hline
\end{tabular}

Fuente: cuadros de elaboración propia en base al trabajo de campo realizado entre 2004 y 2009 en Ciudad de Buenos Aires.

Por último, María y Cristina integran la categoría de mujeres que migraron con sus familias de procreación. En ambos casos migraron con sus hijos, pero sin sus compañeros. María, nacida en Villa Ballester, provincia de Buenos Aires, llegó a la Capital Federal en 1997 como consecuencia de la disolución de su matrimonio luego de sufrir violencia física y psíquica. Cristina decidió 
desplazarse de Santa Fe hacia Buenos Aires en 1993 en busca de tratamiento médico para la enfermedad de su hijo menor. Desde entonces vive junto a su hijo, en una habitación de un hotel ubicado en el barrio porteño de Barracas (ver Cuadro 3).

\section{Cuadro 3}

Las mujeres entrevistadas que migraron hacia Buenos Aires con sus familias de procreación

\begin{tabular}{|l|l|l|l|l|l|l|}
\hline Nombre & $\begin{array}{l}\text { Edad al } \\
\text { momento de } \\
\text { la migración }\end{array}$ & $\begin{array}{l}\text { Año de } \\
\text { llegada a } \\
\text { Buenos } \\
\text { Aires } \\
\text { origen }\end{array}$ & $\begin{array}{l}\text { Lugar de } \\
\text { desplazamiento }\end{array}$ & $\begin{array}{l}\text { Cantidad de } \\
\text { años en } \\
\text { Ciudad de } \\
\text { Buenos Aires } \\
\text { al momento } \\
\text { de la } \\
\text { entrevista }\end{array}$ & $\begin{array}{l}\text { Edad al } \\
\text { momento } \\
\text { de la } \\
\text { entrevista }\end{array}$ \\
\hline María & 35 años & 1997 & $\begin{array}{l}\text { Conurbano } \\
\text { (Villa } \\
\text { Ballester, } \\
\text { partido de } \\
\text { San Martín) } \\
\text { (urbano) }\end{array}$ & $\begin{array}{l}\text { Separación y escape. } \\
\text { menores. }\end{array}$ & 10 & $\begin{array}{l}45 \text { años en } \\
2007\end{array}$ \\
\hline Cristina & 38 años & 1993 & $\begin{array}{l}\text { Santa Fe } \\
\text { (semi- } \\
\text { urbano) }\end{array}$ & $\begin{array}{l}\text { En busca de tratamiento } \\
\text { médico para la } \\
\text { enfermedad de su hijo } \\
\text { menor. }\end{array}$ & 14 & $\begin{array}{l}52 \text { años en } \\
\text { enong }\end{array}$ \\
\hline
\end{tabular}

Fuente: cuadros de elaboración propia en base al trabajo de campo realizado entre 2004 y 2009 en Ciudad de Buenos Aires.

El motivo del traslado suele ser distinto en varones y mujeres. Los hermanos, parejas o maridos de las entrevistadas llegaron a Buenos Aires por su propia decisión, en busca de mejoras laborales; desde un punto de vista sociológico puede decirse que actuaron los factores de “expulsión” de su lugar de origen, pues la falta de oportunidades los obligó a emigrar.

\section{La sociedad receptora}

Las migraciones trasladan a varones y mujeres a escenarios desconocidos donde los lazos culturales, si se reimplantan, lo hacen en conflicto con los elementos nuevos de las culturas urbanas (Sarlo, 1994). De modo que se distancian de la cultura de origen en la que fueron socializados. Así, la integración en la ciudad se ve limitada por esa distancia cultural que activa resistencias internas a las que se suman los obstáculos que les impone el medio.

Habituados a una vida más tranquila y con menos sobresaltos, la adaptación al ritmo urbano es particularmente dificultosa para los migrantes. Ya en la ciudad, las mujeres migrantes y sus familias 
comenzaron a sentir el desarraigo, las tensiones del traslado y las dificultades de la radicación.

La diversidad de matrices culturales se hace presente en la Ciudad de Buenos Aires como resultado de la presencia de diferentes grupos poblacionales. Se trata de una ciudad ciertamente polifónica que alberga múltiples culturas, poblaciones portadoras de lenguajes, costumbres y creencias diferentes que expresan diversos usos y modos de apropiación del espacio. "El migrante en la ciudad ha incorporado nuevas perspectivas y puntos de vista. Puede volver al pago pero ya no es parte del mismo. En el ámbito urbano el migrante encara el desafío de construir un nuevo arraigo" (Ameigeiras, 2006, p. 292). Es decir, la matriz cultural identitaria de estas migrantes de sectores populares no se altera cualitativamente, sino que se va transformando y se generan respuestas y estrategias adaptativas a la nueva situación. "Su identidad se recompone, se readapta y se redefine sobre la base de conservar lo esencial de su antigua identidad y de la matriz cultural que le sirva de soporte” (Santos Jara, 1991; citado en Giménez, 1996, p. 25).

La clase de vida que una lleva allá [en Corrientes] es muy diferente a la que una tiene acá, porque allá andás lo más tranquilo, lo más pancho y acá andás a 200. Acá perdí mis amistades. Me duele un poco porque siempre estábamos todos juntos en Esquina. Algún día si tengo la oportunidad de irme de paseo lo voy a hacer, pero ir a quedarme a vivir allá, no lo haría (Susana).

Mi niñez fue re linda, en el barrio éramos una barrita de chicos, jugábamos a la escondida, salíamos a andar en patines y patineta, jugábamos en la calle. Todos éramos de la cuadra. Los domingos íbamos a la casa de mi abuela y se juntaban todos los tíos (...) No me volvería porque allá no hay trabajo. De vacaciones siempre fui, pero no me volvería (Silvia).

La sociabilidad característica de los pequeños pueblos de provincia en los que se privilegia el núcleo más cercano de familiares y amigos se pierde, en gran medida, cuando se pasa a habitar en el centro de una gran metrópoli en la que predominan relaciones de carácter impersonal y prevalece la alienación, la fragmentación y el individualismo. Es necesario reconocer, entonces, las dolorosas consecuencias que trae el proceso de reacomodación a la sociedad receptora, y reconocer también que la experiencia migratoria genera impactos emocionales y sufrimientos que afectan las trayectorias vitales.

Según las entrevistadas, vivir en la ciudad les permite acceder a beneficios y consumos que no encuentran en sus lugares de origen. "Estar cerca de todo” las hace sentir parte de la dinámica de la ciudad y no excluidas de ella. En reiteradas ocasiones manifiestan no querer volver a su provincia natal; su lucha cotidiana radica en ser reconocidas por los sectores medios de la población como “merecedoras” de la ciudad y en tener acceso a los beneficios que brinda la metrópoli.

La cercanía y el fácil acceso al lugar de trabajo, las instituciones educativas, los hospitales y los diversos medios de transporte son las ventajas que brinda vivir en zonas céntricas de la ciudad. Las mujeres entrevistadas habitan, por su residencia en hoteles-pensión, en un entorno social más moderno y urbano. Instaladas en barrios céntricos de la Ciudad de Buenos Aires se distancian de la subcultura creada por los miembros de su sector social en la sociedad receptora donde suelen reconstituir -en cierta forma- la comunidad de origen, sus vínculos, prácticas y costumbres. El 
nuevo hábitat las envuelve e inserta, hasta cierto punto, en la cultura urbana, y son fuertemente influidas por esta.

\section{Vivir en una habitación de hotel}

Los hoteles-pensión surgen en Buenos Aires en la década de 1950 debido al estancamiento de los conventillos. Esto se produjo ya que, desde la década del '40, las sucesivas leyes de control de alquileres aplicadas contribuyeron eficazmente a su decadencia. Desde entonces, los conventillos como fuentes de generación de renta urbana dejaron de ser un negocio para sus propietarios pues, al no poder fijar libremente sus precios en el mercado, vieron muy disminuidas sus ganancias. Con la aparición de los hoteles-pensión surge una mutación del submercado de habitaciones basada en la búsqueda de rentabilidad y la evasión del control estatal (Pastrana, Bellardi, Agostinis y Gazzoli,1995, p. 15).

Al tener la condición legal de hoteles, los habitantes de estos establecimientos no son considerados inquilinos sino "pasajeros” o "huéspedes”. Es decir, habitantes temporales -en términos legales, pero no reales- que, por lo tanto, no pueden acogerse a la protección de las leyes de alquileres ${ }^{4} \mathrm{y}$ sobre quienes el hotelero está autorizado a ejercer su derecho de admisión y desalojo. Además, por quedar exentos de la legislación de alquileres, los precios de arriendo de las habitaciones pueden ser aumentados sin que rija un control de precios por parte del Estado. Así, el alquiler de piezas de hotel como forma aggiornada de los inquilinatos supone una fuente de obtención de renta urbana. La intención de los propietarios es extraer la mayor renta posible de sus edificios completamente deteriorados aprovechando su ubicación en las zonas más céntricas de la ciudad y las ventajas que esta localización supone para los inquilinos.

Los hoteles-pensión constituyen una inversión más rentable que un conventillo. Las tarifas hoteleras son superiores al monto de alquiler de una pieza de inquilinato; se cobra alquiler por cama o por habitación; el cobro se hace por adelantado en forma diaria o semanal, y los huéspedes pueden ser desalojados por falta de pago de manera inmediata. Son verdaderos conventillos encubiertos que funcionan con el nombre de hotel, pero en realidad no prestan ninguno o casi ninguno de los servicios que se requieren para entrar en dicha categoría $a^{\underline{5}}$. Las condiciones de vida son iguales o peores a las de un inquilinato. Son edificios vetustos que se caracterizan por un alto grado de hacinamiento y bajas condiciones de salubridad, combinados con un precio desproporcionado en relación a las características del alojamiento.

Desde su surgimiento, los hoteles suponen un modo precario de vivir en la ciudad. Sus condiciones de habitabilidad han empeorado década tras década, signadas por la precariedad y la inseguridad jurídica. Esto se debe a varios factores, como el deterioro continuo y la falta de mantenimiento e inspección de los edificios, el crecimiento de la demanda de habitaciones sumado a la falta de espacio en los inmuebles para solventarla, la convivencia de varias personas en una misma habitación, los reiterados conflictos entre inquilinos y encargados, y la ausencia de un marco legal que permita incluir a los habitantes de hotel en la figura de inquilinos. En nuestros registros de campo, hemos observado que, en una misma habitación que no supera los $10 \mathrm{~m}^{2}$, conviven hasta nueve personas en hacinamiento crítico. Los estrechos e inadecuados espacios comunes, sumados al 
reducido tamaño de las piezas, en las que conviven hacinados, padres, hijos y a veces algunos parientes llevan a un mínimo la intimidad de las familias.

El ambiente hogareño no está dividido en espacios especializados; se trata de habitaciones que sirven simultáneamente como alcoba, comedor y sitio de estar. En un mismo espacio se superponen múltiples actividades, como las comidas diarias mientras miran la televisión, los juegos de esparcimiento y las tareas escolares de los niños y adolescentes, las discusiones y peleas de los adultos y también su vida sexual. Así, la falta de privacidad favorece los roces y la irritabilidad, lo que configura un estado de conflictividad en la vida diaria de las familias.

Mi hijo, desde que estamos en esta pieza, perdió su libertad. Yo no lo dejo salir al patio porque hay chicos más grandes y le pasan por arriba con la bicicleta o con la pelota. Está todo el día acá adentro (Roxana).

Las nenas [sus hijas] no se crían bien. Imaginate ella, está todo el día acá dando vueltas, no tiene lugar para moverse. Mili me dice, “yo no quiero vivir más acá, yo quiero tener una casa”. Claro porque ella va a ver a otras compañeritas que por ahí la invitan a jugar y tienen casa. Además no tenés intimidad. En este hotel nadie respeta a nadie. Ponen la música fuerte a cualquier hora. Acá al lado hay una pareja que se matan a palos todo el día. Es tierra de nadie. Esto no es vida y lamentablemente los chicos tienen que ver esto y es un ambiente feo (Silvia).

En cuanto a la estructura edilicia de los hoteles, la mayoría no cumple con las condiciones mínimas de habitabilidad e higiene. En nuestras cotidianas visitas observamos la falta de agua caliente, el deterioro físico de los edificios, el cableado eléctrico al aire, la humedad en las habitaciones y un alto grado de hacinamiento. Los inquilinos están obligados a pasar gran parte del día en espacios comunes. La mala ventilación, los ambientes húmedos, la oscuridad y la falta de privacidad son algunos de los aspectos que caracterizan a una pieza de hotel.

Es horrible vivir en hoteles, no tendrían que existir. La terraza no tiene medianera, cualquiera se puede caer. El gas ahí está conectado con cosas raras que ellos hicieron. Metrogs vino a sacar el medidor. Estuvimos como dos días sin gas (Silvia).

Este hotel se cae a pedazos. Acá las desventajas son que tengo que ir media cuadra hasta el baño y media cuadra hasta la cocina. A veces se me quema la comida porque me entretengo haciendo otra cosa. Y para bañarse ahora en invierno se te congela todo. Además, acá hay un gran problema. Por orden municipal no se pueden recibir visitas en las habitaciones (Alicia).

Una situación paradójica es la percepción de las mujeres entrevistadas según la cual vivir en un hotel es una situación transitoria y aun de emergencia, lo que contrasta con una realidad objetiva que evidencia estadías prolongadas. Alquilar una pieza de hotel, en lugar de ser una solución provisoria y de corto plazo para atenuar el problema habitacional, parecería haberse convertido en la solución permanente para una problemática perdurable. A esto se suman las restricciones a la posibilidad de acceso a otras alternativas habitacionales, en particular el alquiler de departamentos, debido a la inestabilidad económica de las mujeres inquilinas. Vivir en hoteles no es una elección 
sino una decisión obligada.

Algunas mujeres perciben la habitación de hotel como su casa, otras sólo como un lugar de paso aunque registren varios años de estadía en estos establecimientos. De todos modos, aunque el hotel aparece como "el espacio contingente al que nadie se siente perteneciente” (Pastrana et al., 1995, p. 80), existe un proceso de transformación y resignificación del espacio por parte de los moradores que favorece la configuración de las identidades. Así, la pieza es el lugar de la apropiación, un espacio domesticado que se ha hecho propio: sus habitantes se preservan, entre sus paredes, de los conflictos cotidianos. Es un refugio precario, pero refugio al fin. En este sentido, cada habitación tiene impresas las huellas del paso de los otros y de los que actualmente viven en ella. Son no lugares transformados en lugares $\underline{\underline{6}}$.

Recién ahora te puedo decir que acá adentro de mi habitación me siento cómoda. A mí me gusta de hecho estar acá, en esta habitación. Mi casa es esta pieza. Cuando yo salgo afuera es otra cosa. Acá adentro lo considero mi lugar, acá yo me siento a gusto. Pero cuando recién llegué me quería ir al otro día (Roxana).

Yo lo siento mi casa. Al principio me costó pero después me adapté. Acá no tenés a quien reclamarle nada porque no hay encargado. También me costó adaptarme acá a Buenos Aires (Lidia).

Esta pieza es mi casa. Mi nieta dice, cuando está afuera, "vamos a la casita, abuelita” (Cristina).

Si tuvieran la oportunidad de abandonar el hotel, las mujeres entrevistadas mencionaron como alternativas habitacionales la posibilidad de acceder a una vivienda propia a partir de la participación en una cooperativa de vivienda -de hecho, cinco de ellas forman parte de estas organizaciones-, o por medio de un plan de vivienda, aunque la ausencia de políticas y planes de vivienda impulsados por el gobierno porteño transforma el deseo de abandonar los precarios hoteles en una utopía.

Estas mujeres con sus familias de procreación han perdido su mobiliario entre mudanza y mudanza, pues generalmente las habitaciones se alquilan amobladas (camas, sillas, mesa y en ocasiones armarios). Además, son tan pequeñas que muchas veces se ven obligadas a guardar sus pocas pertenencias en depósitos. Sólo la heladera ${ }^{7}$, el televisor y algún otro electrodoméstico adquiridos con gran esfuerzo suelen ser de su propiedad. Al proyectar un futuro, estas mujeres siempre persiguen el ideal del techo propio.

Pasar de hotel en hotel fue un trastorno familiar, aparte psicológico también porque no estás estable en ningún lado y la meta de uno es quedarte estable en un lugar y no salir más. Los chicos dicen: “iAy! ¡mami!, ¿por qué nos tenemos que ir y por qué nos venimos acá?”, y bueno tenés que explicarles los motivos y las razones y todo. El proyecto mío que de a poco se va cumpliendo es de tener mi casa. Poco a poco lo voy concretando. El día que yo me muera sé que me voy a morir tranquila porque sé que yo he hecho mi casa, que he llegado al logro que tanto anhelaba yo y que tanto quería y que después va a quedar para los chicos (Marta). 
Yo quería echar raíces en algún lado pero no podía, iba de hotel en hotel. Una vez estuve en uno que, no sólo no aceptaban chicos, sino que era un desastre, había gente que tomaba y se agarraban a piñas y no quería vivir más ahí (Silvia).

Podríamos considerar que las mujeres entrevistadas y sus familias conforman hogares con Necesidades Básicas Insatisfechas (NBI) o se encuentran por debajo de la línea de pobreza, si tomamos en cuenta su nivel de ingresos. Muchas de ellas perciben y han percibido algunos de los diversos planes sociales, como el Plan Jefas y Jefes de Hogar, la Asignación Universal por Hijo, el Programa Nuestra Familia, la tarjeta Ciudadanía Porteña, y subsidios habitacionales de todo tipo. Algunas además reciben asistencia de Cáritas (alimentos, ropa, mobiliario, etc.), o de parroquias y comedores, entre otras instituciones.

Dentro del mismo campo de los hoteles-pensión coexisten distintas situaciones de inquilinos: aquellos que rentan la habitación y aquellos que son subsidiados por el Gobierno de la Ciudad de Buenos Aires (sea pagando la habitación al hotelero, sea otorgando subsidios habitacionales a las familias) (ver Cuadro 4). Estos últimos se encuentran en una posición económicamente desventajosa respecto de los primeros, pues no disponen de empleos estables y, por lo tanto, carecen de la posibilidad de destinar un porcentaje de sus ingresos al arriendo de una habitación. Sin embargo, aunque todos los residentes en hoteles tienen similares problemas habitacionales condiciones de hacinamiento, precariedad edilicia, falta de intimidad y conflictos permanentes con el/la encargado/ $a^{\underline{8}}$, las entrevistadas enfatizan que existe entre ellos una notoria falta de identificación y reconocimiento mutuo. La ausencia de demandas comunes y el escaso nivel de organización interna desalientan la conformación de lazos solidarios. Se trata de una población que se ha caracterizado históricamente por escasos antecedentes de movilización colectiva en defensa de sus intereses. Según Bellardi (1994, p. 53), el bajo nivel de organización se debe "por una parte, a la autopercepción de esta población de su situación actual en el hotel como transitoria y de emergencia, pero también porque la amenaza de expulsión a través del ejercicio del 'derecho de admisión’ por parte del hotelero emerge cotidianamente”.

\section{Cuadro 4}

Mujeres entrevistadas según establecimiento en el que residen (hotel o inquilinato) y tipo de inquilino

\begin{tabular}{|l|l|l|}
\hline Mujeres entrevistadas & $\begin{array}{l}\text { Establecimiento en el que residen } \\
\text { (hotel o inquilinato) según barrio } \\
\text { (particular o de inquilino } \\
\text { por el GCBA) }\end{array}$ \\
\hline Marta (Mendoza) & Hotel San Carlos-Barracas & Subsidiado \\
\hline Adriana (Córdoba) & Hotel Garay-Constitución & Subsidiado \\
\hline Alicia (Tucumán) & Hotel López-Congreso & Particular \\
\hline Silvia (Córdoba) & Hotel Miraflor-Flores & Subsidiado \\
\hline Roxana (San Juan) & Inquilinato Uspallata-Barracas & Particular \\
\hline Lidia (Salta) & Inquilinato Uspallata-Barracas & Particular \\
\hline
\end{tabular}




\begin{tabular}{|l|l|l|}
\hline Susana (Corrientes) & Hotel Halcón-Balvanera & Subsidiado \\
\hline María (Conurbano) & $\begin{array}{l}\text { Departamento comprado con un } \\
\text { subsidio habitacional de \$A15.000, } \\
\text { Bajo Flores. María fue inquilina de particular y subsidiado } \\
\text { hoteles durante 7 años. }\end{array}$ & \\
\hline Cristina (Santa Fe) & Hotel Rondeau-Barracas & Subsidiado \\
\hline
\end{tabular}

Fuente: cuadros de elaboración propia en base al trabajo de campo realizado entre 2004 y 2009 en Ciudad de Buenos Aires.

Asimismo, es frecuente observar procesos de discriminación en el interior de los mismos hoteles. Por una parte, los inquilinos subsidiados por el Gobierno de la Ciudad de Buenos Aires se sienten discriminados por los moradores particulares; por la otra, los encargados de los hoteles establecen diferencias entre los primeros y los segundos. Del mismo modo, hay un trato hostil entre migrantes internos y migrantes de países limítrofes. También suelen clasificarse entre sí como "vagos” y “cómodos" entre quienes comparten la misma situación de inquilinos subsidiados, lo que refuerza las clasificaciones que reciben del exterior.

La vida cotidiana de las mujeres migrantes entrevistadas y sus familias resulta muy condicionada por este hábitat particular. La inestabilidad habitacional, las malas condiciones edilicias, la convivencia de una familia numerosa en habitaciones pequeñísimas, los espacios compartidos, la relación conflictiva entre inquilinos y encargados de los hoteles inciden en las relaciones familiares y en sus representaciones, los discursos y los modos de actuar de estas mujeres. En sus palabras, en sus gestos se puede apreciar el cansancio y, en cierto modo, la resignación ante esas condiciones de vida. Sin embargo, esto no llega a impulsarlas a querer retornar a sus provincias natales, en realidad sucede lo contrario. Las mujeres expresan una sensación de logro y progreso al comparar su pasado en el pueblo de origen con su vida actual en la ciudad. Si bien el traslado no les ha procurado mejoras económicas significativas ni comodidades en lo que respecta a la vivienda, rescatan el hecho de haber adquirido nuevos saberes y mayor integración social, sobre todo aquellas que participan en cooperativas de vivienda.

Luchan por permanecer en la ciudad, por ser reconocidas como merecedoras de la ciudad. Vivir en la ciudad es un derecho, como señala Henri Lefebvre (1969), es el derecho a gozar de los beneficios de la civilización, a disfrutar del bienestar y de las mayores posibilidades de consumo; o como argumenta Oszlak (1982, p. 16), "el derecho al espacio urbano debe entenderse como un derecho al goce de las oportunidades sociales y económicas asociadas a la localización de la vivienda o actividad”.

Estas mujeres continúan realizando esfuerzos por sobrevivir en una ciudad cada vez más caótica, desordenada y expulsiva. Su lucha cotidiana es por el arraigo en la ciudad, por el reconocimiento social. Para conseguirlo, despliegan astucias en pos del derecho a permanecer y progresar en el espacio urbano. Pretenden influir en las clasificaciones sociales dominantes y, para ello, intentan invisibilizar las marcas de su condición de clase en procura de modos de categorización que les resulten más favorables. Tratan de maniobrar sobre las múltiples clasificaciones sociales como 
manera de disputar su identidad personal (Lacarrieu, 1995).

\section{Palabras finales}

La ausencia de propuestas integradoras de política habitacional dirigidas a los sectores populares, sobre todo migrantes internos y de países limítrofes, incide en la falta de acceso a la vivienda digna. En este sentido, el Estado se desentiende en cuanto a políticas habitacionales destinadas a la integración. Las mujeres migrantes de sectores populares entrevistadas han sido seducidas y atraídas por los beneficios que otorga la gran ciudad, y simultáneamente abandonadas por el Estado, pues los mecanismo de recepción y albergue son escasos. No sólo se les niega el derecho a la ciudad sino también se las despoja del derecho a una vivienda digna y se las “condena” -parafraseando a Loïc Wacquant (2007) - a vivir en viviendas precarias (hoteles-pensión, conventillos y casas tomadas) o en los márgenes de la ciudad (villas miseria, asentamientos urbanos y barrios populares).

A las políticas habitacionales restrictivas para los sectores populares, en cuanto al derecho a vivir en la ciudad $^{\underline{9}}$, se suman una serie de políticas tendientes a la regeneración del espacio urbano en los barrios del sur de la ciudad, barrios en los que históricamente se han asentado estos sectores sociales. Estos procesos de renovación urbana se enmarcan en una reapropiación capitalista de la ciudad. Es decir, el capital financiero y los gobiernos a su servicio entienden que las ciudades deben convertirse en una mercancía de la que se pueden obtener beneficios: el objetivo es vender mejor y más cara la ciudad, como si se tratara de una marca. De hecho, la Ciudad de Buenos Aires tiene su propio logotipo y ha tenido varios slogans durante la actual gestión de gobierno (En todo estás vos; Va a estar bueno Buenos Aires). El espacio urbano se constituye al servicio de una concepción mercantil de la ciudad. De modo que la Ciudad de Buenos Aires, al igual que otras metrópolis, atraviesa un proceso de “fetichización” y se convierte en un "producto” (para pocos) a ser “consumido” (por pocos).

\section{Notas}

1 Para un análisis de las diferencias entre villas miseria y Nuevos Asentamientos Urbanos (NAUs), véase María Florencia Rodríguez, 2009.

2 Fuente: Secretaría de Planeamiento, Ministerio de Desarrollo Urbano de la Ciudad de Buenos Aires, 2013.

$\underline{3}$ Los nombres utilizados son ficticios para resguardar la identidad de las entrevistadas.

4 La Ley 14.821 de julio de 1959 plantea las exclusiones del régimen de alquileres y, entre ellas, se encuentra el hospedaje: "Se entiende por hospedaje, la explotación de un inmueble o parte de él destinada a dar ocupación temporaria de una o más habitaciones, con o sin baño y con o sin cocina, constituya o no una unidad funcional de vivienda, siempre que dicha actividad reúna las siguientes características: a) ser debidamente habilitada y b) dar a los ocupantes servicios de luz, teléfono, 
limpieza, agua corriente, ropa de cama y portería. Dichas características debían ser suministradas a los pasajeros en forma continua” (Rivas, 1991, pp. 33-34). De esta manera los habitantes de estas viviendas quedan excluidos de las leyes de alquileres.

$\underline{5}$ De acuerdo a las normas vigentes, el hotelero está obligado a proveer a los inquilinos toallas y sábanas y a realizar la limpieza de la habitación. Es habitual que las familias prefieran satisfacer por sí mismas las necesidades personales de ropa de cama y toallas. Además, en la medida que la vida transcurre en una sola pieza, el hecho de que el inquilino se haga cargo de realizar la higiene también puede entenderse como una forma de protección a su ya limitada intimidad.

6 Marc Augé (1996), en su estudio acerca de la sobremodernidad, construye un sistema interpretativo en torno a las categorías de lugar y no lugar. La casa, el departamento, la vivienda, como un lugar de protección de la familia, son considerados lugares. El lugar es identificatorio, relacional e histórico; es "el lugar del sentido inscripto y simbolizado, el lugar antropológico": un principio de sentido para aquellos que lo habitan. Los no lugares son espacios que se definen como no relacionales, despojados de las expresiones simbólicas de la identidad y la historia. Son espacios para la circulación de personas y bienes (aeropuertos, autopistas, supermercados, anónimos cuartos de hotel). En estos espacios no se vive, sólo se transita. A nivel legislativo los hoteles-pensión permanecen bajo el tratamiento de hoteles turísticos, y por lo tanto sus habitantes-inquilinos se encuentran en la figura de "huéspedes o pasajeros". De modo que, desde el marco legal, los hotelespensión serían no lugares. Pero si consideramos que sus moradores permanecen en ellos largas estadías transformando sus habitaciones en viviendas, estos espacios pensados en un inicio como lugares de paso, privados de toda expresión de identidad, se tornan lugares.

$\underline{7}$ El espacio de la cocina, cuyo uso es compartido al igual que el baño y el lavadero, sólo consta de algunas hornallas y, a veces, de una cocina. Para conservar los alimentos, los inquilinos deben conseguir una heladera para uso privado y ubicarla en su habitación.

$\underline{8}$ En una de las últimas visitas a los hoteles constatamos que el modo en que muchos encargados ejercen su derecho de admisión consiste en rechazar a familias o mujeres solas con hijos pequeños.

$\underline{9}$ Basta mencionar algunas “acciones” del actual gobierno porteño en materia de política habitacional. En el año 2009 desfinanció la Ley 341 -principal herramienta legislativa para los procesos colectivos autogestionarios de vivienda en la Ciudad de Buenos Aires-, recortó el presupuesto del Instituto de Vivienda de la Ciudad -organismo responsable de ejecutar programas específicos de vivienda destinados a familias de recursos insuficientes- y efectuó violentos desalojos en hoteles-pensión y casas tomadas sin orden judicial y por la fuerza. En cuanto a la ejecución presupuestaria en materia de vivienda social fue cayendo paulatinamente: en 2007 se ejecutó el 87 \% del presupuesto mientras que en 2009 menos del 46 \% y a fines de 2010 no llegó al 20 \% (Autor/a, 2013). Según el jefe de las Oficinas de Orientación al Habitante, dependientes de la Defensoría General de la Justicia porteña, el 80 \% de las consultas son por falta de vivienda y se estima que cada mes unas trescientas personas acuden al organismo en relación con esa problemática (Vivienda, una demanda crónica. Página 12, 01/03/2013. Recuperado de http://www.pagina12.com.ar/diario/sociedad/3-214841-2013-03-01.html). 


\section{Referencias bibliográficas}

Ameigeiras, A. (2006). Migración, religión y diversidad cultural en el contexto urbano. En A. Ameigeiras y E. Jure (comps.), Diversidad cultural e interculturalidad, (pp. 289-298). Buenos Aires: Prometeo - UNGS.

Augé, M. (1996). Los no lugares. Espacios del anonimato. Una antropología de la sobremodernidad. Barcelona: Gedisa.

Baer, L. y Kauw, M. (2016). Mercado inmobiliario y acceso a la vivienda formal en la Ciudad de Buenos Aires, y su contexto metropolitano, entre 2003 y 2013. Revista EURE, 42(126), 5-25.

Bellardi, M. (1994). Inquilinatos y hoteles en Buenos Aires. La trayectoria centenaria del mercado de alquiler de piezas. Medio Ambiente y Urbanización, Año 13, 49, 41-55.

Cacopardo, M. C. (2005). Acerca de las mujeres migrantes en la Argentina: tendencias y mercado de trabajo. En Migraciones, globalización y género en Argentina y Chile. Buenos Aires: CECYM, MEMCH, REPEM.

Cacopardo, M. C. y López, E. (1997). Familia, trabajo y fecundidad de los migrantes de países limítrofes. En Estudios Migratorios Latinoamericanos, 15, 187-217

Carman, M. (2006). La ciudad visible y la ciudad invisible: el surgimiento de las casas tomadas en Buenos Aires. Población y sociedad, 10/1,1 71-108.

Cerruti, M. (2009). Diagnóstico de las poblaciones de inmigrantes en la Argentina, Serie de Documentos de la Dirección Nacional de Población N². Dirección Nacional de Población, Secretaría de Interior / OIM.

Cosacov, N. (2012). Alquileres e inquilinos en la Ciudad de Buenos Aires. Una radiografía. Buenos Aires: Laboratorio de Políticas Públicas.

Cuenya, B. (2016). La política urbana frente a la mercantilización y elitización de la ciudad: algunas reflexiones y referencias a la situación argentina. Cuaderno Urbano, 21(21), 167-194.

Dabenigno, V. y Freidin, B (1997). Mujeres migrantes en Maciel: la pobreza urbana como lugar de destino. En H. Herzer (comp.), Postales urbanas del final del milenio. Una construcción de muchos. Buenos Aires: IIGG, CBC.

Dirección General de Estadística y Censos del Gobierno (2006). Encuesta Anual de Hogares de la Ciudad de Buenos Aires.

Di Virgilio, M. y Gil y de Anso, M. L. (2012). Estrategias habitacionales de familias de sectores populares y medios residentes en el área metropolitana de Buenos Aires (Argentina). Revista de Estudios Sociales, 44, 158-170.

Elizalde, D. (1987). Migración interna en la Argentina. Período 1975/80. Buenos Aires: INDEC.

Freidin, B. (2004). El uso del enfoque biográfico para el estudio de las experiencias migratorias femeninas. En R. Sautu (comp.), El método biográfico (pp. 63-101). Buenos Aires: Editorial de Belgrano. 
Geertz, C. (1987). La interpretación de las culturas. México DF: Gedisa.

Giménez, G. (1996). Territorio y cultura. Estudios sobre las culturas contemporáneas, Año II, 4, 930

Herzer, H. y Di Virgilio, M. (2011). Las necesidades habitacionales en la Ciudad de Buenos Aires: cuántos, quiénes, cómo y por qué. En AAVV. La problemática habitacional en la Ciudad de Buenos Aires, Colección Sociales en Debate, UBA Sociales Publicaciones, Buenos Aires, pp. 5-44.

Instituto Nacional de Estadística y Censos (2010). Censo Nacional de Población, Hogares y Viviendas, Argentina.

Jelin, E. (1976). Migración de las ciudades y participación en la fuerza de trabajo de las mujeres latinoamericanas en el servicio doméstico. Buenos Aires: CEDES, Estudios Sociales.

Lacarrieu, M. (1995). Que los conventillos no mueran: disputas por el espacio barrial. En O. Grillo, M. Lacarrieu y L. Raggio, Políticas sociales y estrategias habitacionales. Buenos Aires: Espacio Editorial.

Lattes, A. (2007). Esplendor y ocaso de las migraciones internas. En S. Torrado (comp.) Población y bienestar en la Argentina del primero al segundo centenario: una historia social del siglo XX. Buenos Aires: Edhasa.

Lefevbre, H. (1969). El derecho a la ciudad. Barcelona: Península.

Maguid, A. (2005). La migración internacional en el escenario del Mercosur: Cambios recientes, asimetrías socioeconómicas y políticas migratorias. En Estudios Migratorios Latinoamericanos, Año 19, 57, 249-285.

Maguid, A. y Arruñada, V. (2005). Explorando el impacto de la crisis en la inmigración limítrofe hacia el área metropolitana de Buenos Aires. En VIII Jornadas Argentinas de Estudios de Población. Tandil: AEPA.

Mallimaci Barral, A. (2013). Construyendo comunidades. De las formas y sentidos comunitarios producidos por los/as bolivianos/as en Ushuaia. Estudios Migratorios Latinoamericanos, s/n 119144.

Mallimaci Barral, A. (2012). Revisitando la relación entre géneros y migraciones. Resultados de una investigación en Argentina. Mora, 18(2), 151-165.

Marcús, J. (coord.) (2017). Ciudad viva. Disputas por la producción sociocultural del espacio urbano en la Ciudad de Buenos Aires. Buenos Aires: Editorial Teseo.

Marcús, J. (2011). La incidencia de las políticas habitacionales en los procesos de jerarquización del espacio urbano (Buenos Aires, 1870-1999). Revista Territorios, 24, 59-76.

Marcús, J. (2009). Vivir en hoteles-pensión de la Ciudad de Buenos Aires. El proceso de construcción de identidad en mujeres migrantes que residen en habitaciones de hotel (Tesis de Doctorado), Facultad de Ciencias Sociales, Universidad de Buenos Aires. Inédita.

Oszlak, O. (1982). Los sectores populares y el derecho al espacio urbano. Punto de Vista, 16, 15-20. 
Pastrana, E., Bellardi, M., Agostinis, S. y Gazzoli, R. (1995). Vivir en un cuarto: inquilinatos y hoteles en el Buenos Aires actual. Medio Ambiente y Urbanización, Año 14, 50-51

Recchini de Lattes, Z. (1988). Las mujeres en las migraciones internas e internacionales, con especial referencia a América Latina. Buenos Aires: Cuadernos del CENEP, No. 40.

Rivas, E. (1991). Mercado y submercado de vivienda (alquiler de habitación). En R. Gazzoli (comp.), Inquilinatos y hoteles (pp. 33-46). Buenos Aires: Centro Editor de América Latina, Serie Biblioteca Política Argentina, No. 328.

Rodríguez, M. F. (2009). Notas sobres los conceptos de los Nuevos Asentamientos Urbanos (NAUs) en la Ciudad de Buenos Aires. Revista Pampa, 5, 197-217.

Rosa, P. (2012). “Ser” habitante de la Ciudad Autónoma de Buenos Aires (experiencias y procesos de una ciudad en transformación). Boletín Científico Sapiens Research, 60-65.

Sarlo, B. (1994). Culturas populares, viejas y nuevas. En Escenas de la vida posmoderna. Buenos Aires: Ariel.

Sautu, R. (2004). Estilos y prácticas de la investigación biográfica. En R. Sautu (comp.), El método biográfico. La reconstrucción de la sociedad a partir del testimonio de los autores (pp. 21-61). Buenos Aires: Lumiere.

Sennet, R. (2000). La corrosión del carácter. Buenos Aires: Anagrama.

Secretaría de Planeamiento, Ministerio de Desarrollo Urbano (2013). Mercado inmobiliario de la Ciudad de Buenos Aires. Precio de oferta de venta de terrenos. Ciudad de Buenos Aires.

Svampa, M. (2005). La sociedad excluyente: la Argentina bajo el signo del neoliberalismo. Buenos Aires: Taurus.

Wacquant, L. (2007). Los condenados de la ciudad. Gueto, periferias y Estado. Buenos Aires: Siglo XXI. 